\title{
Development and Validation of the Acculturative Stress among Iranian Diaspora Scale
}

\section{Farimah Dokoushkani}

Department of Human Ecology, Research Group of Environment and Human Studies, Iran

\section{Rumaya Juhari}

Family, Adolescent, and Child Research Center of Excellence (FACE), Faculty of Human Ecology, Universiti Putra Malaysia, Malaysia

\section{Abbas Abdollahi}

Department of Counseling, Faculty of Education and Psychology, Alzahra

University, Tehran, Iran

\section{Seyed Mehdi Motevaliyan}

Faculty of Humanities and Social Sciences, University of Mazandaran, Iran

\section{Randle A. Villanueva}

Department of Psychology, Clemson University

\section{Zhuo Job Chen}

Department of Psychology, Clemson University

\section{Abstract}

The current study's aims were to develop and validate a measure of acculturative stress among Iranian diaspora population. The instrument of 27 items was administered to a total of 610 Iranian students studying in Malaysian universities. Exploratory and confirmatory factor analyses offered evidence for a reliable and valid six-factor construct that assess a range of stresses for Iranian diaspora: 
1) Concern about finances and a desire to stay in any country except Iran (CF); Language difficulties (LD); 3) Interpersonal stress (IS); 4) Stress from new culture and desire to return to Iran (SNC); 5) Academic pressure (AP); and 6) Stress from new rules and regulations (SNR). This measure was among the first to assess acculturative stress among an Iranian diaspora population and may be useful in future studies.

Keywords: measurement development; acculturative stress; Iranian population; immigration; diaspora; stress

Address all correspondence to Dr. Job Chen at 418 Brackett Hall, Clemson, SC 29634.Email:zhuoc@clemson.edu

The people of the Middle East's many countries have been subject to migration away from their homes due to financial crises, ethnic conflict, and sociopolitical dissent, which all either stem from or culminate in violence and war (Sahin, 2010). Consequently, many children, adolescents, and caregivers are subject to experiencing reduced mental wellbeing (e.g., depression, anxiety, PTSD) from the stressful and traumatizing effects of war (Dimitry, 2011; Murthy \& Lakshminarayana, 2005). In search of escape from life in an unstable world, Malaysia, a highly multicultural society, has found itself as a host to these individuals who go in the hopes of a better life than one in their home country (Hugo, 1993).

In the last few decades, Iran has become one of the top ten immigrantsending countries (Naghdi, 2010) and Malaysia remains a popular destination for Iranian immigrants given the relative ease of entry, and with tourist visas granting up to three months stay (Rahmandoust et al., 2011); perhaps more importantly, is Malaysia's perceived similarity in religion and culture (Fozi, 2013). Many, if not most, of these Iranians left Iran due to the fallout of the Iranian revolution of 1979 and the Iran-Iraq War, with hundreds of thousands seeking personal freedom from an oppressive government (Ghorashi \& Boersma, 2009). The largest population of Iranian immigrants are studying in Malaysian universities (Moslemi Naieni, 2013). These students are subject to experiencing immense turmoil along multiple socio-cognitive domains due to experiencing a major shift into a new, unfamiliar culture. Past research on immigrant youth has found this type of transition from a singular culture to a multi-cultural environment can result in numerous emotional, behavioral, and psychological adjustment problems (Arbabi, Yeh, Mahmud, \& Salleh, 2017).

Many Iranian migrants will need to come to terms with stark differences between their values and those of their new environments. Perhaps the most salient is that immigrating Iranian families have to deal with broken family ties, and loss of social status; for many, immigration means breaking ties with the 
Iranian culture (e.g., loss of ability to use original language or eat traditional foods; Jalali, 2005). For example, some participants have reported that style of dress and appearance do not carry as much social weight as it did in Iran, which leads to a lot of confusion about understanding socioeconomic status differences between people or evaluating one's own social worth (Arbabi, et al., 2017). There are also changes in culture that might not be as clear to outside observers of cultural intermingling, such as stress induced by failing to understand nonverbal cues that once held inverse meanings in Iran (Arbabi, et al., 2017).

These differences even extend so far as nuances in religion and interactions with religious individuals. On a societal level, the government has been reported to treat Muslims differently depending on their ethnic origin (Martin, 1991). Moving to a narrower scope, individuals express discomfort in disclosing information regarding their religious beliefs, which is a norm in Malaysia but not in Iran, and will often resort to isolating oneself to avoid such distressing encounters (Arbabi, et al., 2017). These experiences culminate in acculturative stress which encompasses the stress reaction in response to dealing with life events rooted in the experience of acculturation in a new culture. Although this concept carries both negative (e.g., distress) and positive (e.g., eustress) connotations, its negative aspect has been more pronounced in previous studies (Sam \& Berry, 2006).

Acculturative stress is even more salient among international students, given a combination of stressors including differences in academic styles, social alienation at school, and communication problems (Banumathy \& Vikneswaran, 2008). In addition, Embong (2013) suggested that one of the greatest challenges faced by these students are problems with visa requirement, an issue that harkens back to the start of the Iranian diaspora and the negative view of Iran that Western society had (Ghorashi, Boersma, 2009), and compliance to all immigration rules and regulation in their newfound home. Strict immigration policies not only add to the dire financial situations international students often have, but also create uncertainties with respect to where to live and work after finishing school. Furthermore, their daily lives necessitate that they integrate themselves into society in order to adjust more effectively in sociocultural and psychological domains. As international students they are engaged in unfamiliar heterogeneous environments for large portions of their days and require that they interact with dissimilar others, adding to psychological strains (Arbabi, et al., 2017).

All together, these experiences of acculturative conflict culminate and impose threateningly on the wellbeing of immigrant individuals. Acculturative stress in immigrants has been found to relate to negative outcomes, such as anxiety (Lee, Koeske \& Sales, 2004), depression, suicidal ideation (Hovey, 2000), and worsening of existing symptoms (Sirin, Ryce, Gupta, \& Rogers- 
Sirin, 2013). Thus, acculturative stress can act as a powerful decaying factor for the mental health of immigrants. Therefore, the current proposed measure is intended to function as a culturally sensitive assessment tool in evaluating this important aspect of the mental health of the impacted Iranian populations that are dealing with a profound and major shift in culture and life.

\section{Measures of Acculturative Stress}

Several instruments have been developed to assess acculturative stresses among immigrants including, as described in Table 1. Among them are 1) the instrument to assess levels of acculturative stress among Latin-American immigrants in Spain developed by Hernández, Hernández, and González (2011); 2) the Multidimensional Acculturative Stress Inventory (MASI; Rodriguez, Myers, Mira, Flores, \& Garcia-Hernandez, 2002); 3) the Acculturative Stress Index (ASI; Noh \& Avison, 1996); 4) the Acculturative Stress Scale for International Students (ASSIS; Sandhu \& Asrabadi, 1994); 5) the Demands of Immigration Scale (DIS; Aroian, Norris, Patsdaughter, \& Tran, 1998); 6) the Index of Life Stress (ILS; Yang \& Clum, 1995); and 7) the scale to measure acculturative stress in Social, Attitudinal, Familial, and Environmental Contexts (SAFE; Padilla, Wagatsuma, \& Lindholm, 1985). Among these measures, only three focus on international students as diaspora (i.e. ASSIS, ILS, and SAFE), whereas none reflect the unique patterns of life stresses for Iranian diaspora population.

\section{Current Study}

Based on the reported statistics by Ministry of Higher Education in Malaysia, approximately $14 \%$ of international students in Malaysia come from Iran (MoHE, 2011). No studies have yet assessed acculturative stress among the Iranian immigrants and no instrument has been tailored to measure this population specifically. The present study seeks to fill this void with the development of a measure of acculturative stress among Iranian diaspora studying in Malaysian universities.

\section{Method}

\section{Participants}

Based on the list of approved foreign universities provided by Ministry of Science, Research, and Technology of Iran (2015), the degrees from five public 


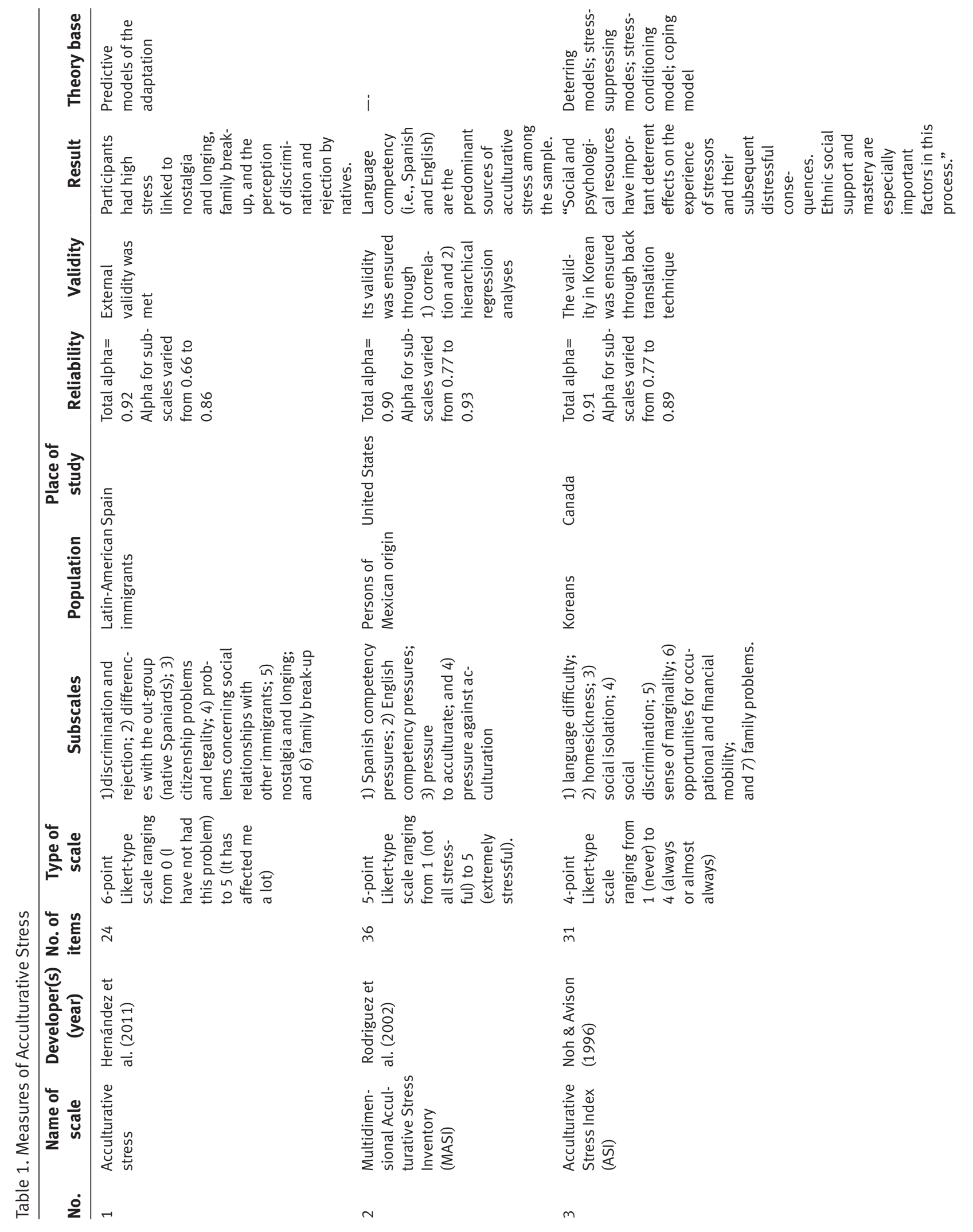




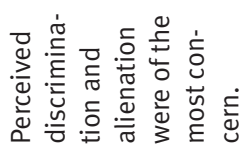

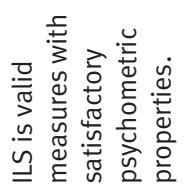

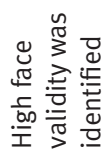

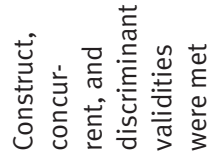

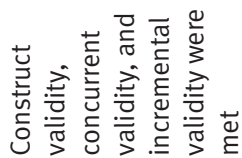

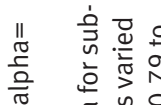

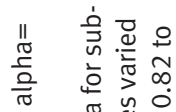

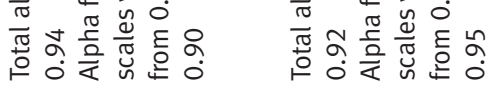

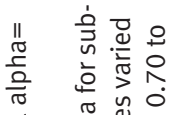

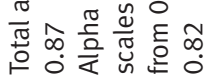
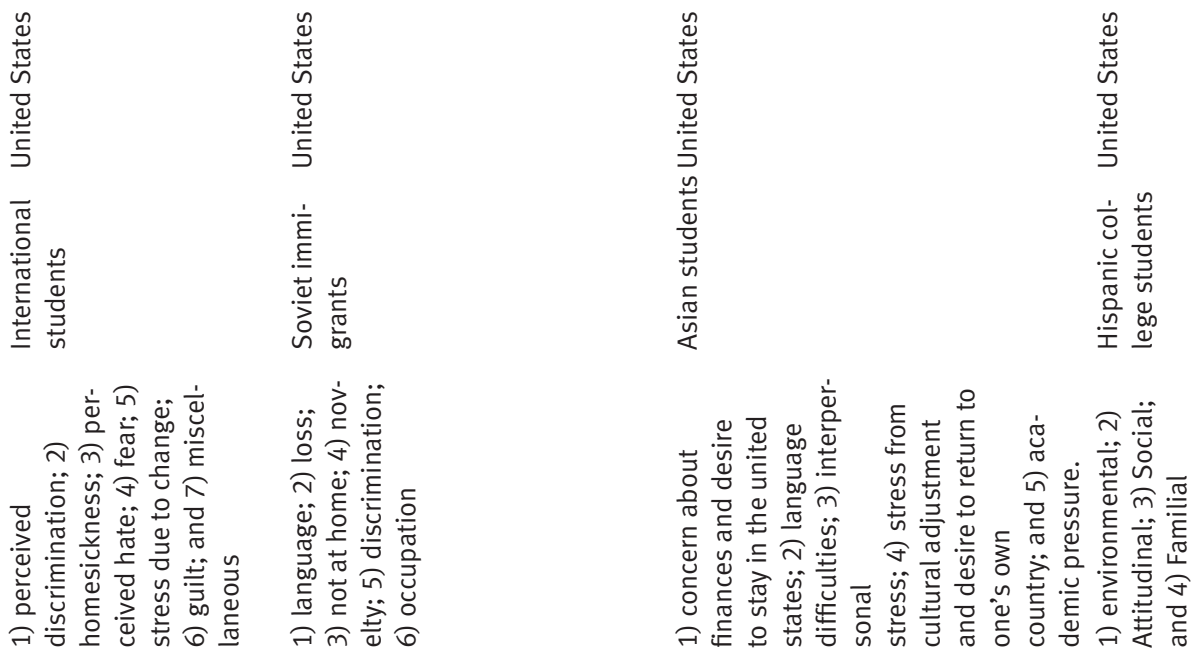

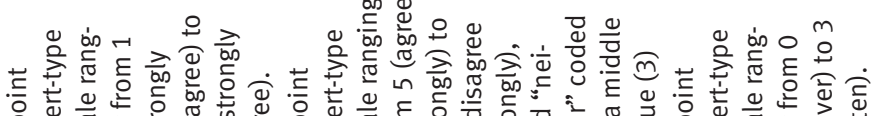

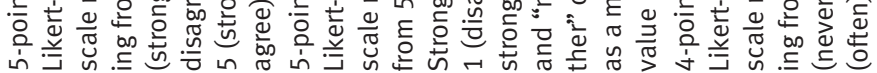

$\stackrel{\varphi}{m}$

ฟ

$\vec{m}$

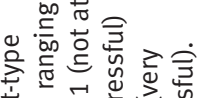

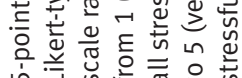

N

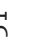

웅
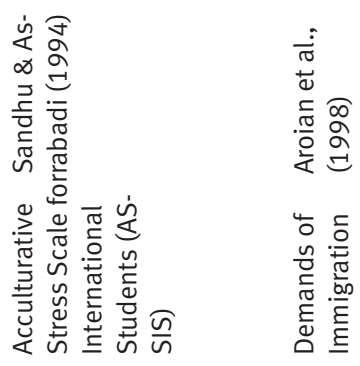

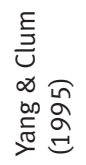

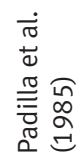

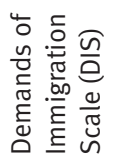

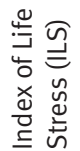

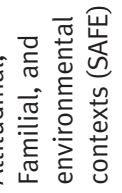

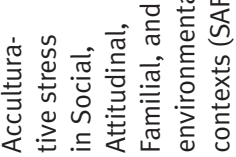

6 
higher education institutions (HEI) in Malaysia are recognized: Universiti Putra Malaysia (UPM), Universiti Teknologi Malaysia (UTM), Universiti of Malaya (UM), Universiti Kebangsaan Malaysia (UKM), and Universiti Sains Malaysia (USM). In this study, Iranians studying in these universities were considered to be source subjects. A total of 647 Iranian students, selected by a multi-stage random sampling approach, were invited to participate voluntarily. The final data included 610 participants who completed the study. The sampling procedure and the criteria to be eligible to participate in the current study is presented in Figure 1. The participants' age ranged from 21 to 58 years old with a mean of 34 years.

\section{Acculturative Stress for Iranian Diaspora Scale (ASID)}

We created the Acculturative Stress for Iranian Diaspora Scale by modifying the Index of Life Stress (ILS) developed by Yang and Clum (1995). The ILS was originally a 31 -item measure of stressful life events designed especially for East Asian international students in the United States of America, rated on a 4 -point scale (from $1=$ never to $4=$ often). Factor analysis indicated that the items grouped into five interpretable categories of stressful events: 1) financial concerns and desire to stay in the United States of America, 2) language difficulties, 3) interpersonal stress, primarily due to the effects of racism, 4) stress from new culture and desire to return one's own country, and 5) academic pressure. Yang and Clum (1995) reported test-retest reliability (one-month interval) for the total scale of 0.87 , and internal reliability (KR-20) of 0.86 .

In the present study, some items were deemed unfit for Iranian Muslim population and were therefore screened out. Some items that did not apply, appeared redundant, or had high content overlap with other items, were also removed. The remaining items were reworded to suit our target population. A list of detailed changes is presented in Table A1 in supplementary materials. A panel composed of five subject matter experts in the field of psychology and sociology evaluated whether the items of ASID assess defined content (content validity) and appear relevant to the research participants (face validity). The final version was double-confirmed by George Clum, the developer of ILS. The final of Acculturative Stress for Iranian Diaspora Scale contained 27 items and was administered to participants in the current study.

\section{Data Collection Procedure}

The English version of ASID scale had been translated to Farsi following the back-translation procedure. Prior to actual test, a pilot test was conducted with a sample of 30 individuals to get feedback on the adequacy of the translated version, difficulty in understanding, ambiguity or inadequacies in the ques- 
Target Population: Iranian married students studying at public HEIs in Malaysia and their spouses

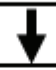

Note: The public HEIs in Malaysia accepted by Science and Technology

Ministry of Iran were including UM, UKM, UPM, USM, and UTM.

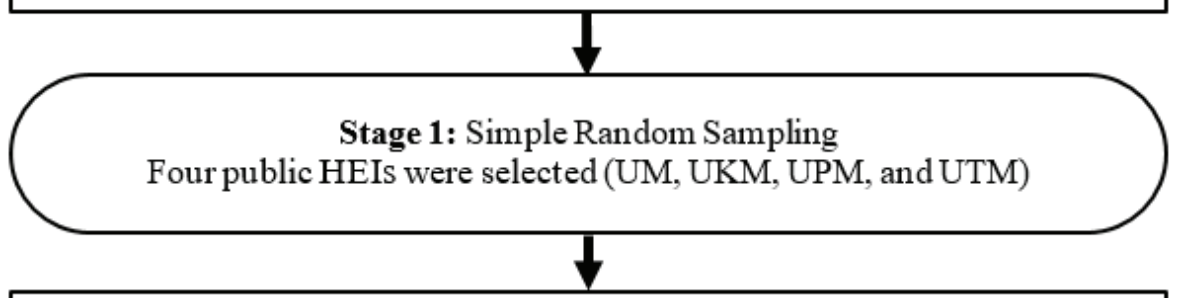

Accessible Population: Iranian students in UM, UKM, UPM, and UTM

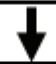

Initial Sample Frame Lists: Provided by the Schools of Graduate Studies of the selected Malaysian public HEIs

Stage 2: Systematic Random Sampling (based on the sampling frame)

Criteria: 1) the length of residence in Malaysia had to be one year or longer,

2) being in Malaysia at the time of data collection, and 3) self-identified as a Muslim

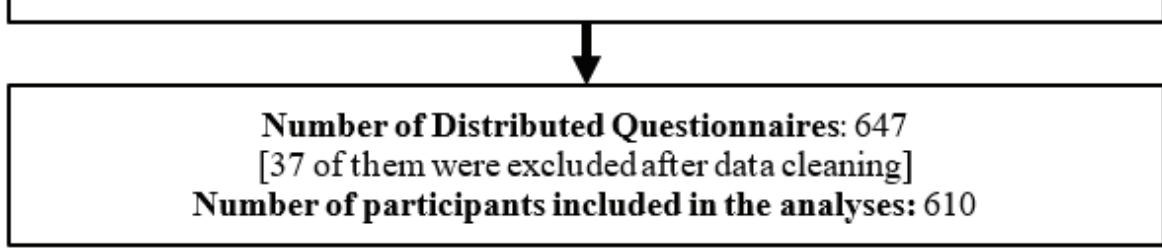

Figure 1. Sampling procedure

tions, the non-response rate to be expected, and the time frame needed to complete the questionnaires (Portney \& Watkins, 2000). The Cronbach's alpha was found to be 0.85 for the full scale.

In the actual test, drop-off and pick-up (DOPU) self-administered questionnaire method was applied (Allred \& Ross-Davis, 2011) where the researcher clarified the aims of the study, and promised discretion and anonymity. 
Moreover, the participants were told that the goal of the research was to gain a better understanding of the acculturative stress that Iranian students encounter during the time that they are living in Malaysia. All participation was voluntary. The study complied with the rules and was approved by the ethical committee of University Putra Malaysia.

\section{Results}

Prior to conducting the main statistical analyses, we screened the data for outliers, normality, and missing values. All individual items met standards of univariate normality as outlined by Tabachnick and Fidell (2013). Out of 647 collected questionnaires, 610 completed responses were used in the final data analyses.

\section{Exploratory Factor Analyses (EFA)}

We applied EFA on half of the data to detect dimensionality of ASID scale. Factors were extracted using maximum likelihood estimation with Varimax rotation. To facilitate interpretation, results focused on item loadings greater than .40 .

The 27 items of ILS were loaded on six factors comparable to those of ILS. The six factors were named concern about finances and a desire to stay in Malaysia or any country except Iran (CF); 2) Language difficulties (LD); 3) Interpersonal stress (IS); 4) Stress from new culture and desire to return to Iran (SNC); 5) Academic pressure (AP); and 6) Stress from new rules and regulations (SNR). These six factors explained $60.89 \%$ of total variance. As shown in Table 2, all factors loaded with values greater than .60. This finding was satisfactory taking into account the fact that average explained variance of a factor structure in psychological measures is usually between 50\% and 60\% (Hair, Black, Babin, Anderson, \& Tatham, 2009).

\section{Confirmatory Factor Analysis (CFA)}

We then fit a second-order confirmatory factor model to the other half of the data in AMOS 21.0. As described in Figure 2, individual items loaded on six respective latent subscale factors, which in turn loaded on an overall latent variable. The overall model fit was adequate, $\mathrm{CMIN} / \mathrm{df}=1.40, \mathrm{GFI}=0.96, \mathrm{CFI}=$ 0.96 , IFI $=0.96$, and RMSEA $=0.04$ (Hair et al., 2009). Standardized factor loadings showed that all items loaded on their respect factors with moderate to large effect size, ranging from 0.47 to 0.75 for the second-order factor and ranging from 0.61 to 0.90 for the first-order factors. 
Table 2. Factor loadings matrix for ASID scale

\begin{tabular}{|c|c|c|c|c|c|c|}
\hline & SNC & CF & LD & IS & AP & SNR \\
\hline $\begin{array}{l}\text { 4. I worry about whether I will have a secure future } \\
\text { career in Iran. }\end{array}$ & 0.87 & & & & & \\
\hline $\begin{array}{l}\text { 2. I feel uncomfortable with the culture differences } \\
\text { in Malaysia. }\end{array}$ & 0.86 & & & & & \\
\hline $\begin{array}{l}\text { 23. I want to go back to Iran in the near future, but } \\
\text { I may not be able to do so. }\end{array}$ & 0.76 & & & & & \\
\hline $\begin{array}{l}\text { 12. I don't like the things people do for their enter- } \\
\text { tainment here. }\end{array}$ & 0.73 & & & & & \\
\hline $\begin{array}{l}\text { 20. I haven't become used to enjoying the Malay- } \\
\text { sian holidays. }\end{array}$ & 0.73 & & & & & \\
\hline 9. I feel uncomfortable to adjust to new foods. & 0.68 & & & & & \\
\hline 18. I don’t enjoy listening to Malaysian music. & 0.62 & & & & & \\
\hline $\begin{array}{l}\text { 19. I worry about my future: will I return to Iran, or } \\
\text { stay in Malaysia or go to another country. }\end{array}$ & & 0.87 & & & & \\
\hline 17. I worry about our financial situation. & & 0.85 & & & & \\
\hline $\begin{array}{l}\text { 21. I don't want to return to Iran, but I may have to } \\
\text { do so. }\end{array}$ & & 0.81 & & & & \\
\hline $\begin{array}{l}\text { 13. I worry about whether I will have my future } \\
\text { career in another country (except Iran). }\end{array}$ & & 0.75 & & & & \\
\hline 24. My financial situation makes my life here very & & 0.72 & & & & \\
\hline
\end{tabular}
hard.

1. My English language level embarrasses me when I talk to people.

7. My English makes it hard for me to read articles, books, etc. (or understand English TV programs).

22. My English-language deficiency makes it hard for me to communicate with others.

15. I can't express myself well in English.

0.75

0.75

0.73

10. People treat me unfairly just because I am a foreigner.

8. I don't have a good feeling with the ways people treat each other here.

11. I think that people are very inconsiderate here.

5. I can feel racial discriminations toward me from others.

6. I am not doing as well as I want to in university.

16. It would be the biggest shame for me if I fail in university.

3. I worry about my academic performance.

14. I study very hard in order not to disappoint my family.

27. I worry about limited health insurance coverage.

25. I worry about breaking unfamiliar rules and regulations of the country. 


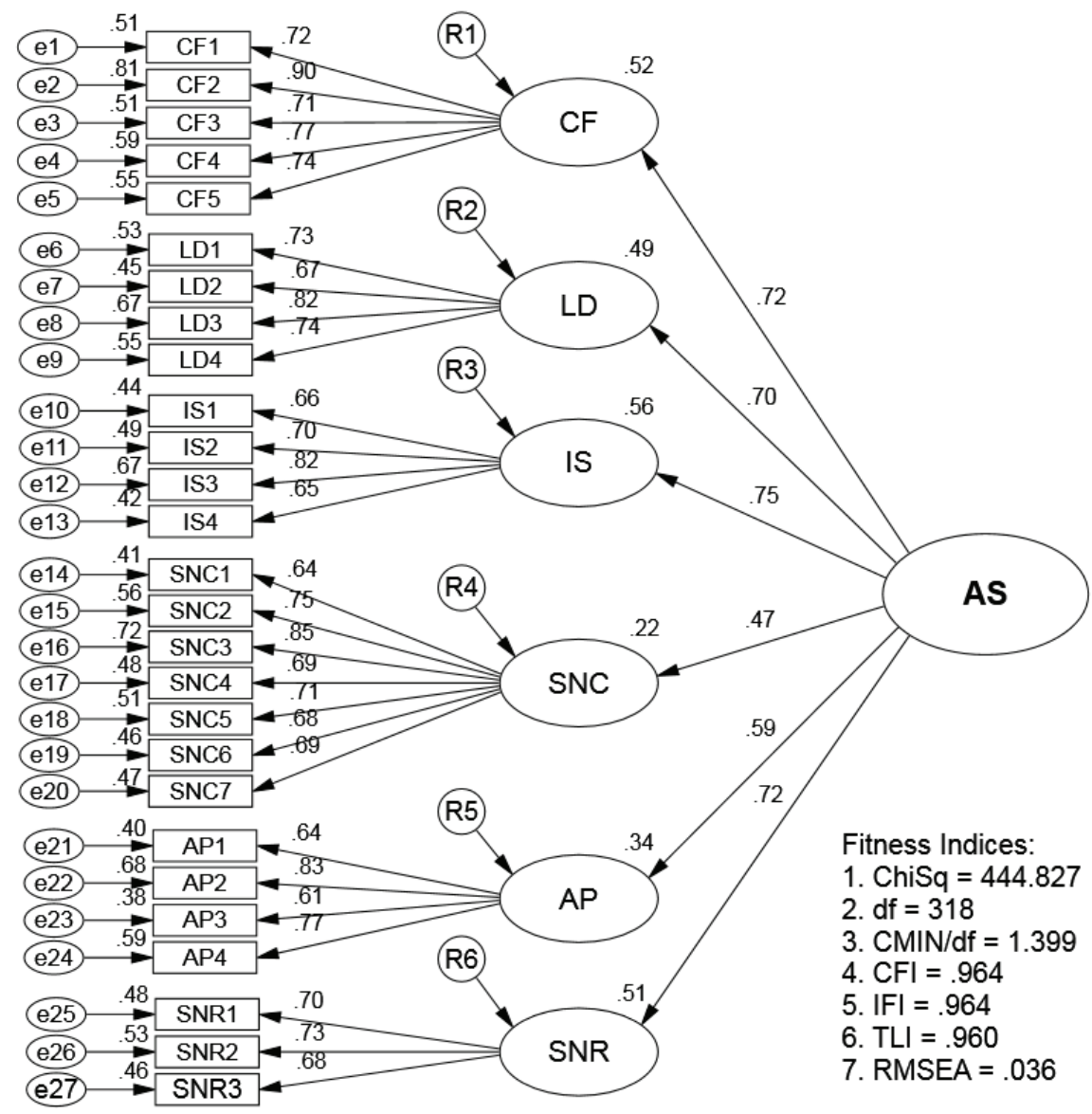

Figure 2. Second-order measurement model for acculturative stress construct

Abbreviations: $A S=$ Acculturative Stress; $C F 1$ to $C F 5=$ Indicators of Concern about Finances and a desire to stay in Malaysia or any country except Iran; LD1 to LD4= Indicators of Language Difficulties; IS1 to IS4= Indicators of Interpersonal Stress; SNC1 to SNC7= Indicators of Stress from New Culture and desire to return to Iran; AP1 to AP4= Indicators of Academic Pressure; SNR1 to SNR3= Indicators of Stress from New Rules and Regulations; $\mathrm{CMIN} / \mathrm{df}=$ Minimum discrepancy divided by degrees of freedom; CFI= Comparative Fix Index; IFI= Incremental Fit Index; TLI= Tucker Lewis Index; RMSEA= Root Mean Square Error of Approximation.

In addition, the Average Variance Extracted (AVE) values, with values equal to or greater than 0.50 can serve as evidence for convergent validity (Kline, 2010). The AVE values for the first-order factors CF, LD, IS, SNC, AP, and SNR were $0.60,0.55,0.51, .52,0.52$, and 0.50 respectively, and .44 for the second-order factor. Finally, reliability was calculated using $C R$ value that should be equal to or greater than 0.60 (Kline, 2010). The CR value for SNR was 0.75 and for the other five sub-constructs were above 0.80 , indicating acceptable reliability. 


\section{Discussion}

The current study developed a measure of Acculturative Stress for Iranian Diaspora by modifying the more generalized ILS to better understand and assess the cultural challenges faced by Iranian immigrant students. The findings of this study suggested that the structure ASID in the Iranian population is best explained by a six-factor solution as a multidimensional scale, and the total scale can be used to indicate overall acculturative stress. Correlations among the 27 items did not exceed 0.695 (Table A2 correlation matrix is available upon request), suggesting that those items measure something in common but are distinct enough from each other.

The six factors replicated and extended previous factor structures based on ILS. The first factor, CF, reflects the reality constraint faced by international students in Malaysia who have limited access to any employment opportunities. Hence, financial difficulty has been one of the predominant problems experienced by Iranian students in Malaysia (Thomas \& Althen, 1989). In addition, outlook for the future was unpredictable for immigrant students, who were constantly concerned about looking for jobs elsewhere. The second factor, LD, reflects the fact that English is not the native language for most Iranian students, and English language proficiency was found as an important determinant of international students' adjustment, over age, sex, and education (Heath, 1970). Moreover, it reflects the known difficulties that Iranian students experience due to living in a multicultural society where multiple languages of even further differing dialects and accents is understood to worsen their acculturative stress (Arbabi, Yeh, Mahmud, \& Salleh, 2017).

The third factor, IS, points to racial discrimination often experienced by students living in a foreign country. One consequence of experiencing discrimination is that it can actually impede one's ability to acculturate, resulting in even greater stress and, thus, negative mental health outcomes (Berry, Phinney, Sam, \& Vedder, 2006). The fourth factor, SNC, reflects that cultural differences between Iran and Malaysia can be a source of stress for Iranian immigrant students. For instance, difficulties in accommodating to food, holidays, and entertainments in Malaysia can be considered stressful life events for Iranian students. The fifth factor, AP, suggests that academic concerns have been a major stressor for students. International students may be more sensitive to their academic performance given their minority status and, therefore, they may experience greater academic pressure than their Malaysian peers. Similar patterns of comparative awareness have been found in previous research as well, with this facet demonstrating to be one of the top acculturation-related concerns of students (Arbabi, et al., 2017). The sixth factor, SNR, relate to stresses from familiarizing with rules and regulations of the new country, the long process of visa issuance, and limited health insurance coverage faced by international 
students in Malaysia. These stresses can present themselves as an ever-present fervor of duress due to the inherently complicated and time-consuming bureaucratic processes involved. Resolving issues of receiving visas or elongating presence in Malaysia may take upwards of months that students may not be able to afford, thereby lending itself to increasing an individual's sense of instability.

These findings suggested that ASID can be used as a culturally sensitive, and relatively comprehensive measure of acculturative stress among Iranian diaspora in particular, and Muslim diasporas in general. However, there could be variance due to sampling from other non-student population, and from Iranian diaspora-immigrants living in other Muslim societies. Future studies can address these concerns with more generalizable samples. Nevertheless, the present study does produce a measure that can be invaluable in understanding the mental health among these types of dispersed immigrants with a fuller cultural context. For research concerned with better studying the underlying roots of mental health issues in Muslim immigrant populations, it is necessary to be able to parse out these acculturative-specific causes out from other more general causes (e.g., financial stress in general versus financial stress due to having no substantial legal status to find work). Moreover, considering the immense influence the process of immigration and acculturation has on how individuals engage in their day-to-day lives, the importance of understanding the overarching cultural context cannot be understated, especially for such a vulnerable and understudied population.

\section{References}

Allred, S. B., \& Ross-Davis, A. (2011). The drop-off and pick-up method: An approach to reduce nonresponse bias in natural resource surveys. Small-Scale Forestry, 10(3), 305-318. https://doi.org/10.1007/s11842-010-9150-y

Arbabi, K., Yeh, C. J., Mahmud, Z., \& Salleh, A. (2017). From monocultural to multicultural: Adaptation of Iranian immigrant adolescents in Malaysia. Journal of Adolescent Research, 32(3), 371-402. https://doi.org/10.1177/0743558416630811

Aroian, K. J., Norris, A. E., Patsdaughter, C. A., \& Tran, T. V. (1998). Predicting psychological distress among former Soviet immigrants. International Journal of Social Psychiatry, 44(4), 284-294. https://doi.org/10.1177/002076409804400405

Banumathy, D., \& Vikneswaran, N. (2008). In K. Sarjit, S. Morshidi, \& A. Norzaini (Eds.), Globalization and internationalization of higher education in Malaysia. Penang, Malaysia: Universiti Sains Malaysia Press.

Berry, J. W., Phinney, J. S., Sam, D. L., \& Vedder, P. (2006). Immigrant youth: Acculturation, identity, and adaptation. Applied Psychology: An International Review, 5593), 303-332. https://doi.org/10.1111/j.1464-0597.2006.00256.x

Dimitry, L. (2011). A systematic review on the mental health of childrenand adolescents in areas of armed conflict in the Middle East. Child Care Health Development, 38(2), 153-161. https://doi.org/10.1111/j.1365-2214.2011.01246.x 
Embong, A. R. (2013). Responding to Globalization and the State: Negotiations and Contestations by the Middle Class in Malaysia Globalization and Social Transformation in the Asia-Pacific (pp. 63-77): Springer. https://doi.org/10.1057/9781137298386_5

Falavarjani, M. F., \& Yeh, C. J. The impact of acculturation identification and acculturative stress on creativity among Iranian immigrants living in Malaysia. Journal of Ethnic and Migration Studies, 44(13), 2219-2239. https://doi.org/10.1080/136918 3X.2017.1366301

Fozi, N. (2013). The Iranian Diaspora in Malaysia: Emergent Pluralism. Jul 10, 2013. Retrieved from http://www.mei.edu/content/iranian-diaspora-malaysia-emergent-pluralism

Ghorashi, H. \& Boersma, K. (2009). The 'Iranian Diaspora' and the new media: From political action to humanitarian help. Development and Change, 40(4), 667-691. https://doi.org/10.1111/j.1467-7660.2009.01567.x

Hair, J. F., Black, W. C., Babin, B. J., Anderson, R. E., \& Tatham, R. L. (2009). Multivariate data analysis: A global perspective (7th ed.). Upper Saddle River: Prentice Hall.

Heath, G. L. (1970). Foreign student attitudes at international house, Berkeley. International Educational and Cultural Exchange, 5(3), 66-70.

Hernández, J. A. R., Hernández, G. T., \& González, Á. R. (2011). Acculturative stress in Latin-American immigrants: an assessment proposal. The Spanish journal of psychology, 14(01), 227-236. https://doi.org/10.5209/rev_SJOP.2011.v14.n1.20

Hovey, J. D. (2000). Acculturative stress, depression, and suicidal ideation among Central American immigrants. Suicide and Life-Threatening Behavior, 30(2), 125-139. doi: 10.1111/j.1943-278X.2000.tb01071.x

International Students' Association (ISA). (2014, June 7) Common concerns among international students in Malaysia.

Jalali, B. (2005). Iranian families. In N. Garcia-Preto, J. Giordano, \& M. McGoldrick (Eds.), Ethnicity \& family therapy (pp. 451-467). New York: The Guilford Press.

Kline, R. B. (2010). Principles and pactice of structural equation modeling (3rd ed.). New York: Guilford Publications.

Lakshminarayana, R. \& Murthy, R. S. (2006). Mental health consequences of war: a brief review of research findings. World Psychiatry, 5(1), 25-30.

Lee, J., Koeske, G. F., \& Sales, E. (2004). Social support buffering of acculturative stress: a study of mental health symptoms among Korean international students. International Journal of Intercultural Relations, 28(5), 399-414. https://doi.org/10.1016/j. ijintrel.2004.08.005

Martin, P. L. (1991). Labor migration in Asia. The International Migration Review, 25(1), 176-193. https://doi.org/10.1177/019791839102500108

Ministry of Higher Education Malaysia (MoHE). (2011). Internationalisation Policy for Higher Education Malaysia. In M. M. o. H. E. M. Putrajaya (Ed.).

Ministry of Science Research and Technology of Iran. (2015). List of approved foreign universities. Retrieved from http://grad.saorg.ir/Credential-Evaluation-Book/ After-May-2013/

Moslemi Naieni, H. (2013). Announcement of Ministry of Science, Research and Technology of Iran about the number of Iranian students abroad. Retrieved December 9, 2013 http://scholarship.msrt.gov.ir/news/270-1391-11-30-15-42-11

Naghdi, A. (2010). Iranian diaspora: with focus on Iranian immigrants in Sweden. Asian Social Science, 6(11), 197-208. https://doi.org/10.5539/ass.v6n11p197

Noh, S., \& Avison, W. R. (1996). Asian immigrants and the stress process: A study of Koreans in Canada. Journal of Health and Social Behavior, 192-206. https://doi. $\operatorname{org} / 10.2307 / 2137273$ 
Padilla, A. M., Wagatsuma, Y., \& Lindholm, K. J. (1985). Acculturation and personality as predictors of stress in Japanese and Japanese-Americans. The Journal of social psychology, 125(3), 295-305. https://doi.org/10.1080/00224545.1985.9922890

Portney, L. G., \& Watkins, M. P. (2000). Foundations of clinical research: applications to practice (Vol. 2). Upper Saddle River, NJ: Prentice-Hall Inc.

Rodriguez, N., Myers, H. F., Mira, C. B., Flores, T., \& Garcia-Hernandez, L. (2002). Development of the Multidimensional Acculturative Stress Inventory for adults of Mexican origin. Psychological Assessment, 14(4), 451. https://doi.org/10.1037/10403590.14.4.451

Sahin, Z. (2017, November 30). Ethnicity, Nationalism, and Migration in the Middle East. Oxford Research Encyclopedia of International Studies. Ed. Retrieved 22 Nov. 2018, from http://internationalstudies.oxfordre.com/view/10.1093/acrefore/9780190846626.001.0001/acrefore-9780190846626-e-174.

Sam, D. L., \& Berry, J. W. (2006). The Cambridge handbook of acculturation psychology. New York: Cambridge University Press. https://doi.org/10.1017/ CBO9780511489891

Sandhu, D. S., \& Asrabadi, B. R. (1994). Development of an acculturative stress scale for international students: Preliminary findings1. Psychological reports, 75(1), 435448. https://doi.org/10.2466/pr0.1994.75.1.435

Tabachnick, B. G., \& Fidell, L. S. (2013). Using Multivariate Statistics (6 ed.). New York: Pearson.

Thomas, K., \& Althen, G. (1989). Counseling foreign students. In P. B. Pedersen, J. G. Draduns, W. J. Lonner, \& J. E. Trimble (Eds.), Counseling across cultures (3rd ed., pp. 205-241). Honolulu, HI: University of Hawaii Press.

Yang, B., \& Clum, G. A. (1995). Measures of life stress and social support specific to an Asian student population. Journal of Psychopathology and Behavioral Assessment, 17(1), 51-67. https://doi.org/10.1007/BF02229203 
